\title{
Effectiveness of a community-based integrated care ward (CICW) on 90-day readmission among the elderly people: a retrospective cohort study of a rural area in Japan
}

\author{
Keiichi Shimatani $^{1 *}$, Tatsuya Hiraki ${ }^{2 *}$, Kyoichi Deguchi ${ }^{3}$, and Koji Ono ${ }^{1}$ \\ ${ }^{1}$ Division of Nursing, Higashigaoka Faculty of Nursing, Tokyo Healthcare University, Japan \\ ${ }^{2}$ National Hospital Organization Hamada Medical Center, Japan \\ ${ }^{3}$ National Hospital Organization Kagoshima Medical Center, Japan
}

\begin{abstract}
Objective: Community-based integrated care wards (CICW) play a role in supporting the return of patients to their homes. However, studies investigating the readmission risk associated with CICW are lacking. To investigate the influence of CICW on readmission, we conducted a retrospective cohort study among Japanese elderly people.

Materials and Methods: This study used data from the Diagnosis Procedure Combination (DPC) and medical records of the Hamada Medical Center, Shimane Prefecture in 2014-2019. The number of subjects and readmission in each hospitalization case (general ward only [GW] and CICW) were 1,521 and 416 subjects and 152 and 49 cases, respectively. We selected the hospitalization cases for heart failure (I30-I52), ischemic heart disease (I20-I25), pneumonia (J09-J18), chronic lower respiratory tract diseases (J40-J47), intestinal diseases (K55-K64), cerebrovascular disease (I60-I69), gallbladder, bile duct, and pancreatic diseases (K80-K87) from the International Statistical Classification of Diseases and Related Health Problems (ICD-10). The hazard ratios (HRs) and $95 \%$ confidence intervals (CIs) for readmission via a CICW were estimated using a multivariate Cox proportional hazards model.

Results: The HRs for readmission associated with CICW were not different between the shorter and longer durations, considering the percentage of CICW stay. Compared with GW cases, the HR of CICW cases was 0.40 (95\% CI, 0.17-0.92) in coordination with outside agencies of hospital discharge support. While the HR of GW cases was 2.35 (95\% CI 1.01-5.47), a significantly increased risk was observed in people living alone. A similar risk was not observed in CICW cases with the HR of 0.56 (95\% CI 0.15-2.07). Conclusion: The present study observed decreased risk of readmission among the patients discharged from CICW, compared to GW. Further research is required to clarify the causal factors for this decreased risk.
\end{abstract}

Key words: readmission, risk, community-based integrated care ward, Japan

Received: December 15, 2020

Accepted: June 23, 2021

*These authors contributed equally.

Correspondence: Keiichi Shimatani, Division of Nursing, Higashigaoka Faculty of Nursing, Tokyo Healthcare University, 2-5-1 Higashigaoka, Meguro-ku, Tokyo 152-8558, Japan E-mail: k1-shimatani@umin.ac.jp

This is an open-access article distributed under the terms of the Creative Commons Attribution Non-Commercial No Derivatives (c) (1) $\Theta$ (by-nc-nd) License $<\mathrm{http} / / /$ creativecommons.org/ BY NC ND licenses/by-nc-nd/4.0/>

\section{Introduction}

In 2006, the Community-Based Integrated Care System was established in Japan. It assists in taking care of elderly people with chronic disease or disabilities in a comprehensive and integrated manner, while containing social security costs to support a super-aging society. The care system aims to ensure that all social services, not just medical and longterm care, are provided seamlessly according to the needs of the residents ${ }^{1-3)}$.

Community-based integrated care wards (CICW) have been newly established since the 2014 medical reimbursement revision, and they play three main roles ${ }^{4}$. The first role 
is sub-acute care, which handles acute exacerbations of patients recovering at home or in long-term-care facilities. The second role is post-acute care that focuses on the continuous treatment and rehabilitation of patients who have completed the acute phase of their care. The third role is supporting the return of patients to their homes. One of the indicators that measure the quality of healthcare provided in a general ward and community-based integrated care is readmission ${ }^{5}$. Several studies reported the evaluations of post-discharge cardiac rehabilitation ${ }^{6}$ ) and readmission prevention approach called Hospital Readmissions Reduction Program, a part of the Obamacare in the United States ${ }^{7}$. Other reports have shown a lower readmission rate among patients with Chronic Obstructive Pulmonary Disease (COPD) who went through post-acute care $^{8)}$ and have also revealed disease factors affecting readmissions ${ }^{7,9-11)}$. A CICW with continuous involvement from the acute to the sub-acute to the chronic and convalescent phases has been considered to contribute the prevention of readmission; however, studies investigating the influence of $\mathrm{CICW}$ on readmission have not been conducted yet, to the best of our knowledge. It is meaningful to evaluate the impact of CICW not only on supporting patients' return home, but also on their subsequent readmissions when considering the future of Japan's healthcare system.

To investigate the effect of $\mathrm{CICW}$ on readmission, we conducted a retrospective cohort study that included Japanese elderly people.

\section{Materials and Methods}

\section{Study area}

The study area, Hamada City, is a regional city located in the western part of Shimane Prefecture with an area of 689.6 $\mathrm{km}^{2}$ and a population of approximately 53,000. The aging rate $\geq 65$ years was $35.7 \%$ in $2017^{12}$. This rate of Shimane Prefecture ranked second highest in Japan in 202013). The region is experiencing declining and aging of its population. The Hamada Medical Center is the only hospital designated as an emergency and critical care in western Shimane Prefecture. The number of emergency outpatients is about 11,000 persons per year and inpatients are about 6,700 persons per year. It is considered to be a core hospital providing acute care in the Hamada Medical District. In Hamada City, no other acute care hospital has the same function, and the Hamada Medical Center is responsible for most of the acute diseases in Hamada City.

\section{Study population and setting}

Hospitalization cases from April 2014 to February 2019 at Hamada Medical Center were collected from the Diagnosis Procedure Combination (DPC; $N=29,159)$. The DPC is a comprehensive per diem payment system based on diagnos- tic group classification for acute inpatient care; DPC data include summary medical record information (sex, date of birth, disease name, disease stage classification, etc.), medical information other than medical insurance treatment, and hospital information (created for each facility). We selected patients who were aged $\geq 65$ years $(\mathrm{N}=19,439)$, then excluded cases of "death" $(\mathrm{N}=1,451)$, "transfer to other hospital," or "discharge to a long-term care or welfare facility" $(\mathrm{N}=3,182)$ at the time of initial discharge. Only cases with a "discharge to home" were selected $(\mathrm{N}=14,806)$.

From previous studies ${ }^{8-11,14)}$, we selected the diseases that have been reported for readmission factors from the International Statistical Classification of Diseases and Related Health Problems (ICD-10): heart failure (I30-I52), ischemic heart disease (I20-I25), pneumonia (J09-J18), chronic lower respiratory tract diseases such as chronic obstructive pulmonary disease (COPD) (J40-J47), intestinal diseases such as intestinal obstruction (K55-K64), and cerebrovascular disease (I60-I69), gallbladder, bile duct, and pancreatic diseases such as cholecystitis and pancreatitis (K80-K87). In addition, only the cases at the time of initial hospitalization by those diseases were selected $(\mathrm{N}=2,954)$. Meanwhile, we excluded planned readmissions if the reason for readmission was scheduled surgery, radiation therapy, chemotherapy, or examinations $(\mathrm{N}=504)$.

To determine the impact of CICW, we also excluded cases transferred to a convalescent rehabilitation ward that had similar functions to those of CICW. The Japanese healthcare system prohibits patients from being admitted to both CICW and convalescent rehabilitation wards during the same hospitalization period $(\mathrm{N}=132)$. For patients with duplicates, priority was given to the initial hospitalizations, and subsequent cases were excluded $(\mathrm{N}=293)$. We thus obtained a total of 2,025 subjects who were included in our study (Figure 1). All these subjects were patients aged $\geq 65$ years, who were either admitted to a general ward only or transferred to a CICW after being admitted to a general ward.

Baseline patient information (age, sex, height, and weight), primary diseases, comorbidities, duration of hospital stay, presence or absence of stay in the CICW, duration of CICW stay, presence or absence of home-based medical care, period to readmission, activities of daily living (ADL), and smoking index were obtained from the DPC. Regarding hospital discharge support, information on discharge support conferences, consultation with patients and families, and collaboration with outside agencies through the intervention of the regional medical liaison office and living arrangement were collected from medical records.

This study was approved by the Institutional Ethics Committee of the National Hospital Organization Hamada Medical Center and the Human Ethics Review Board, Tokyo Healthcare University. 


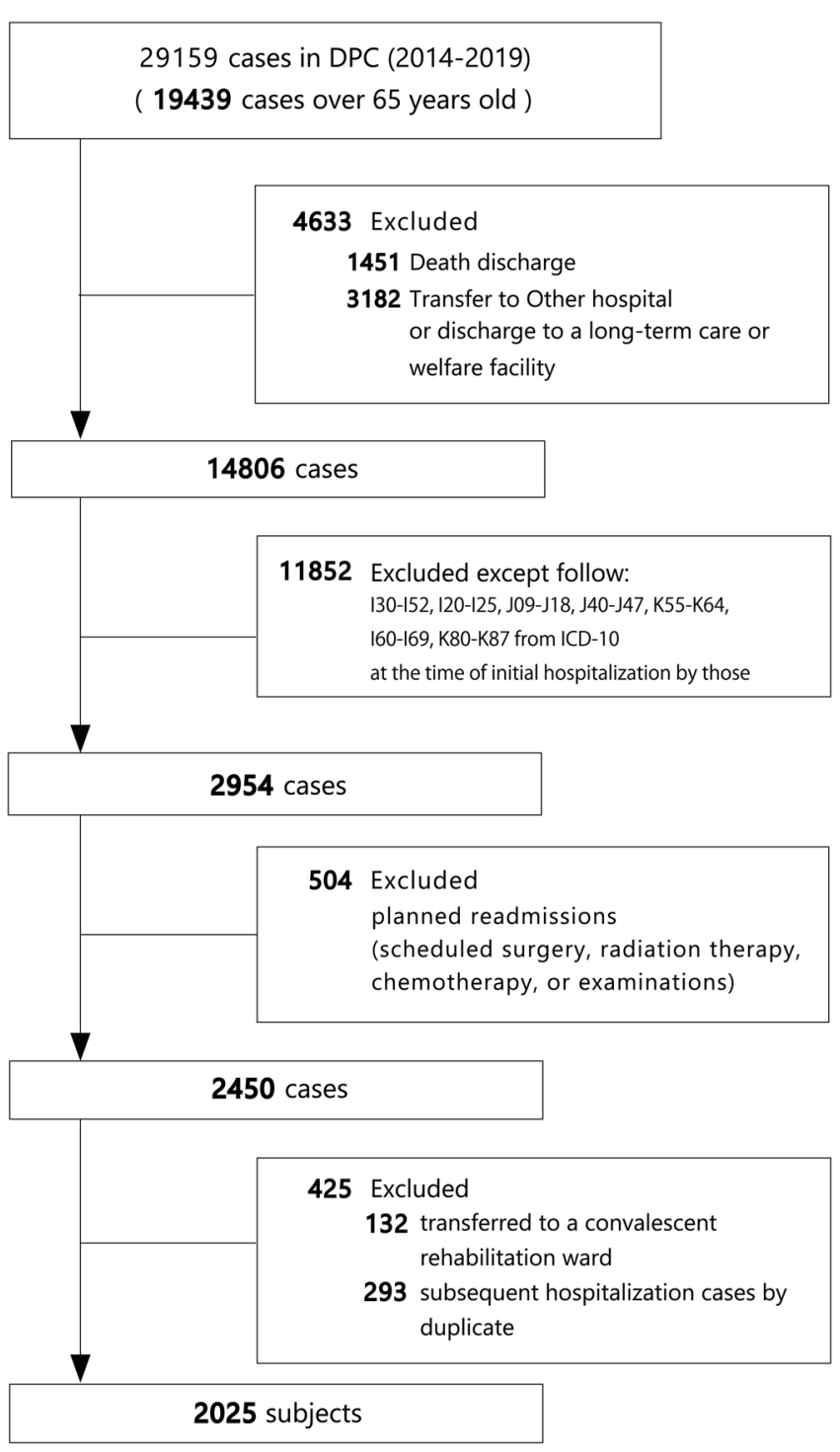

Figure 1 Flow diagram of the study subjects for all hospitalization cases $(\mathrm{N}=29,159)$ collected from a rural hospital in Hamada city. DPC: diagnosis procedure combination; ICD-10: International Statistical Classification of Diseases and Related Health Problems.

\section{Readmission}

We defined the observation period as 90 days after discharge from the hospital and a readmission case as a patient who had an initial hospitalization between April 2014 and November 2018, and a readmission for the same disease within that period. In principle, this is because of the limitation caused by the reduction of basic hospitalization fee and the non-resetting of the admission initiation date in cases of readmission for the same disease within 90 days for Japanese medical service ${ }^{15,16}$. The limitation on the non-resetting of the admission initiation date means, for example, that the maximum period of hospitalization in the $\mathrm{CICW}$ is
60 days, and if a patient is hospitalized for disease A, discharged after 20 days, and then readmitted within 90 days for the same disease, he or she can only stay in CICW for 40 days.

\section{Independent variables}

Body mass index (BMI) was also measured from height and weight. Smoking status was categorized using the Brinkman's index, with 0 being "non-smokers (never)" and 1 or more being "former smokers and current smokers (with smoking)". Comorbidities were identified from previous studies $^{17-19)}$ as factors influencing readmission and selected from ICD-10: diabetes (E10-E14), cerebrovascular disease (I60-I69), COPD (J40-J47), pneumonia (J09-J18), ischemic heart disease (I20-I25), heart failure (I30-I52), and dementia (F00-F09, G30-G32).

ADL scores were used at the time of initial discharge. The 10 items were eating, transfer, dressing, toilet use, bathing, walking, stairs, changing clothes, defecation, and urination, and they were surveyed in the following three levels: independent, partial assistance, and full assistance. In addition, because some subjects had items that were unknown in the ADL assessment, the mean of the total score divided by the number of assessed ADL items was also calculated. Since the adjusted items of bathing are two levels, independent and full assistance, we used 0 points for independent and 3 points for full assistance. The items of transferring and walking on the level ground were further divided into two stages of partial assistance, so the score for independence was 0 , partial assistance 1-2, and full assistance 3 . The other items were scored 0 for independence, 1.5 for partial assistance, and 3 for full assistance.

Regarding hospital discharge support, the information on coordination with "care managers", "home-visiting nurses", and "city hall staff" during hospitalization through the intervention of the regional medical liaison office was collected as coordinating with outside agencies. In addition, it included information on the conduct of discharge support conferences and consultation with families and patients. Those data were collected using a binary variable of yes and no, whether discharge support was provided or not regardless of frequency, number of sessions, and time to be held. Then, information on home-based medical care was also collected using a binary variable. The living arrangement was categorized into two categories: living alone or living with other partners and/or children.

\section{Statistical analysis}

The duration of CICW stay was divided into four groups ( 0 days, $1-7$ days, $8-21$ days, and $\geq 22$ days). The percentage of days spent in the CICW was calculated using the total duration of stay as the denominator and then divided into four groups $(0 \%, 1-35 \%, 35-55 \%$, and $\geq 55 \%)$, referring to 
the distribution of the number of patients. The calculated mean of total ADL scores was divided into four groups according to the interquartile range (IQR) values among noreadmission subjects: independent, low, moderate, and high. The characteristics of the study subjects were compared using the chi-square and T-test for general ward only (GW) and CICW hospitalized cases.

After describing the background characteristics of the study subjects, we used a multivariate Cox proportional hazards model to estimate the hazard ratios (HRs) and 95\% confidence intervals (CIs) of readmission according to $\mathrm{CICW}$. In the multivariate-adjusted model, to control the confounding factors, we adjusted for the following covariates: age, sex, BMI, smoking status, duration of hospitalization, comorbidities, and ADL disabilities. We also adjusted for the primary disease, heart failure or ischemic heart diseases, intestinal diseases or bile dust and pancreatic diseases, as a covariate because of the distribution of diseases in GW showed more cases of heart failure and ischemic heart diseases, and fewer cases of intestinal diseases and bile dust and pancreatic diseases. If the information on a covariate was missing, we handled it as a "missing" category when performing the analysis. Furthermore, the HRs with homebased medical care, hospital discharge support, and living arrangement were separately estimated by a different group of GW and transferred to $\mathrm{CICW}$ cases. A trend test was performed using a Cox proportional hazards model among CICW cases.

$P$-values $<0.05$ were considered statistically significant. Statistical analyses were performed using the Stata software (version 15.1 SE; Stata Corp., College Station, TX, USA).

\section{Results}

Table 1 shows the background characteristics considering the hospitalization status at the beginning of the 90-day observation period. The number of subjects in each hospitalization case (GW and CICW) were 1,521 and 416 subjects, respectively. The percentage of females in sex was higher in $\mathrm{CICW}$ cases $(57.7 \%)$ than that in GW cases $(46.6 \%)$. The 10 -item percentage of ADLs was also higher in CICW cases for all items (eating, transfer, dressing, toilet use, bathing, walking, stairs, changing clothes, defecation, and urination). The distribution of using home medical care after discharge was higher in CICW cases (12.0\%) than in GW cases $(6.0 \%)$, and in all items of hospital discharge support (discharge support conferences, consultation with patients and families, and coordinating with outside agencies), CICW cases revealed higher percentage than GW cases. The percentage of individuals living alone was slightly lower in CICW cases (26.1\%) than that in GW cases (30.7\%).

The number of readmission cases in each hospitalization case (GW and CICW) was 152 and 49 cases, respectively
(Table 2). Bile duct and pancreatic diseases (K80-K87) represented the highest percentage of diseases among readmission cases among GW (45.4\%) and CICW cases (55.2\%). The second highest was heart disease for GW and CICW cases. The mean duration until readmission was 4.5 days longer in CICW cases among readmission cases; however, no statistically significant difference was observed $(P=0.246)$.

The HRs for readmission for those with CICW stay were not significantly different from GW only cases regardless of the frequency and duration of CICW stay, even in multivariate models (Table 3). Decreasing trends in the HRs for readmission with the frequency and duration of CICW stay were not observed ( $P=0.406$ and $P=0.327$, respectively).

The HRs for readmission with home medical care after discharge, hospital discharge support, and living arrangement were separately estimated after the hospitalization cases were divided into $\mathrm{CICW}$ and GW (Table 4). In the multivariate-adjusted model, compared to GW cases, the HR of CICW cases was 0.40 (95\% CI, 0.17-0.92) in coordinating with outside agencies of hospital discharge support, while the HR of GW cases was 2.35 (95\% CI 1.01-5.47), a significantly increased risk was observed in those living alone. A similar increased risk was not observed in CICW cases with the HRs of 0.56 (95\% CI 0.15-2.07). In this model, subjects with unknown living arrangements $(\mathrm{N}=1,393)$ were excluded from the analysis. Increased or decreased risks for readmission with the home medical care after discharge and other hospital discharge support issues were not observed regardless of hospitalization status, either.

\section{Discussion}

To the best of our knowledge, the present study is the first report to investigate the effect of $\mathrm{CICW}$ on readmissions using a longitudinal study design in Japan. Our findings show that there is an increased risk of readmission in patients living alone admitted to GW only, whereas no such association was found in patients transferred to CICW. It was also observed that coordination with outside agencies may contribute to a lower risk of readmission among patients discharged via CICW, regardless of the hospital stay duration.

Previous studies have reported that living alone is a readmission risk factor for the elderly, suggesting that they may be negatively affected by social support and caregiver limitations, resulting in inadequate post-discharge management $^{20)}$. It has been reported that older adults living alone have a poor degree of improvement in ADL, which was lowered at the time of hospitalization, after discharge from the hospital $^{21)}$. Because a continued reduction in ADL after discharge from the hospital makes it difficult to continue living at home, intensive social resources are particularly important for the elderly living alone in discharge planning ${ }^{21)}$. Ad- 
Table 1 Background characteristics of the subjects by hospitalization status

\begin{tabular}{|c|c|c|c|c|c|}
\hline & & & $\begin{array}{c}\text { General Ward Only } \\
\qquad \mathrm{N}=1,521\end{array}$ & $\begin{array}{l}\text { Transferred to CICW } \\
\qquad N=416\end{array}$ & \multirow[t]{2}{*}{$P$ value } \\
\hline & & & \multicolumn{2}{|c|}{ Number (\%) } & \\
\hline \multirow[t]{2}{*}{ Sex } & \multirow{2}{*}{\multicolumn{2}{|c|}{$\begin{array}{l}\text { Male } \\
\text { Female }\end{array}$}} & $812(53.4)$ & $176(42.3)$ & $<0.001$ \\
\hline & & & 709 (46.6) & $240(57.7)$ & \\
\hline \multirow[t]{3}{*}{ Age in years } & \multirow{3}{*}{\multicolumn{2}{|c|}{$\begin{array}{l}65-69 \\
70-79 \\
80-\end{array}$}} & $247(16.2)$ & $39(9.4)$ & $<0.001$ \\
\hline & & & $544(35.8)$ & $112(26.9)$ & \\
\hline & & & $730(48.0)$ & $265(63.7)$ & \\
\hline \multirow[t]{4}{*}{ BMI } & \multirow{4}{*}{\multicolumn{2}{|c|}{$\begin{array}{l}<18.5 \\
18.5-25.0 \\
\geq 25.0 \\
\text { Missing }\end{array}$}} & $208(13.7)$ & $70(16.8)$ & 0.427 \\
\hline & & & $906(59.6)$ & $242(58.2)$ & \\
\hline & & & $306(20.1)$ & $79(19.0)$ & \\
\hline & & & $101(6.6)$ & $25(6.0)$ & \\
\hline \multirow[t]{3}{*}{ Smoking status } & \multirow{3}{*}{\multicolumn{2}{|c|}{$\begin{array}{l}\text { Current / Former } \\
\text { Never } \\
\text { Missing }\end{array}$}} & $121(7.9)$ & $25(6.0)$ & 0.013 \\
\hline & & & $892(58.7)$ & $277(66.6)$ & \\
\hline & & & $508(33.4)$ & $114(27.4)$ & \\
\hline \multirow[t]{38}{*}{ ADL disabilities } & \multirow[t]{4}{*}{ Eating } & Independent & $1,249(82.1)$ & $281(67.6)$ & $<0.001$ \\
\hline & & Partial assistance & $206(13.5)$ & $86(20.7)$ & \\
\hline & & Full assistance & $50(3.3)$ & $40(9.8)$ & \\
\hline & & Unknown & $16(1.1)$ & $9(2.2)$ & \\
\hline & \multirow[t]{4}{*}{ Transfer } & Independent & $1,116(73.4)$ & $230(55.3)$ & $<0.001$ \\
\hline & & Partial assistance & 335 (19.5) & $133(32.0)$ & \\
\hline & & Full assistance & $64(2.6)$ & 49 (11.8) & \\
\hline & & Unknown & $16(0.4)$ & $9(0.9)$ & \\
\hline & \multirow[t]{3}{*}{ Dressing } & Independent & $1,184(77.8)$ & $257(61.8)$ & $<0.001$ \\
\hline & & Full assistance & $320(21.0)$ & $151(36.3)$ & \\
\hline & & Unknown & $17(1.1)$ & $8(1.9)$ & \\
\hline & \multirow[t]{4}{*}{ Toilet use } & Independent & $1,131(74.4)$ & $228(57.2)$ & $<0.001$ \\
\hline & & Partial assistance & $320(19.3)$ & $102(24.5)$ & \\
\hline & & Full assistance & $90(5.9)$ & $66(15.9)$ & \\
\hline & & Unknown & $6(0.4)$ & $10(2.4)$ & \\
\hline & \multirow[t]{3}{*}{ Bathing } & Independent & $1,131(74.4)$ & $228(57.2)$ & $<0.001$ \\
\hline & & Full assistance & $320(19.3)$ & $102(24.5)$ & \\
\hline & & Unknown & $90(5.9)$ & $66(15.9)$ & \\
\hline & \multirow[t]{4}{*}{ Walking } & Independent & $1,077(70.8)$ & $216(51.9)$ & $<0.001$ \\
\hline & & Partial assistance & 293 (19.3) & $105(25.3)$ & \\
\hline & & Full assistance & $91(6.0)$ & $63(15.1)$ & \\
\hline & & Unknown & $60(3.9)$ & $32(7.7)$ & \\
\hline & Stairs & Independent & $1,003(65.9)$ & $193(46.4)$ & $<0.001$ \\
\hline & & Partial assistance & $133(8.7)$ & $47(11.3)$ & \\
\hline & & Full assistance & $87(5.7)$ & $53(12.7)$ & \\
\hline & & Unknown & $298(19.6)$ & $123(29.6)$ & \\
\hline & Changing clothes & Independent & $1,101(72.4)$ & $218(52.4)$ & $<0.001$ \\
\hline & & Partial assistance & $300(19.7)$ & $116(27.9)$ & \\
\hline & & Full assistance & $97(6.4)$ & $73(17.6)$ & \\
\hline & & Unknown & $23(1.5)$ & $9(2.2)$ & \\
\hline & Defecation & Independent & $1,241(81.6)$ & $281(67.6)$ & $<0.001$ \\
\hline & & Partial assistance & $178(11.7)$ & $64(15.4)$ & \\
\hline & & Full assistance & $84(5.5)$ & $64(15.4)$ & \\
\hline & & Unknown & $18(1.2)$ & $7(1.7)$ & \\
\hline & Urination & Independent & $1,227(80.7)$ & $275(66.1)$ & $<0.001$ \\
\hline & & Partial assistance & $183(12.3)$ & $71(17.5)$ & \\
\hline & & Full assistance & $91(6.0)$ & $63(15.1)$ & \\
\hline & & Unknown & $20(1.3)$ & $7(1.7)$ & \\
\hline Home medical care after discharge & Yes & & $88(6.0)$ & $49(12.0)$ & $<0.001$ \\
\hline Hospital Support for discharge & Discharge support & onferences & $230(15.1)$ & $129(31.0)$ & $<0.001$ \\
\hline & Consultation with & tients and families & $121(8.0)$ & $78(18.8)$ & $<0.001$ \\
\hline & Coordinating with & utside agencies & $216(14.2)$ & $130(31.3)$ & $<0.001$ \\
\hline Living arrangement & Living alone & & $106(30.7)$ & $52(26.1)$ & 0.256 \\
\hline & Living with others & & $239(69.3)$ & 147 (73.9) & \\
\hline & Unknown & & $1,176-$ & $217-$ & \\
\hline
\end{tabular}

CICW: community-based integrated care ward; BMI: body mass index; ADL: activities of daily living. 
Table 2 Distribution of diseases ${ }^{\text {a) }}$ at the initial hospitalization and readmission by hospitalization status during the 90-day observation period

\begin{tabular}{|c|c|c|c|}
\hline & $\begin{array}{l}\text { General Ward Only } \\
\qquad \mathrm{N}=1,521\end{array}$ & $\begin{array}{l}\text { Transferred to CICW } \\
\qquad \mathrm{N}=416\end{array}$ & $P$ value \\
\hline & \multicolumn{2}{|c|}{ Number (\%) } & \multirow{9}{*}{$<0.001$} \\
\hline Distribution of diseases at the initial hospitalization & & & \\
\hline Heart failure (I30-I52) & $341(22.4)$ & $42(10.1)$ & \\
\hline Pneumonia (J09-J18) & $160(10.5)$ & $46(10.6)$ & \\
\hline COPD (J40-J47) & $27(1.8)$ & $6(1.4)$ & \\
\hline Ischemic heart disease (I20-I25) & $205(13.5)$ & $5(1.2)$ & \\
\hline Intestinal diseases (K55-K64) & $247(16.2)$ & $107(25.5)$ & \\
\hline Cerebrovascular disease (I60-I69) & $243(16.0)$ & $55(12.5)$ & \\
\hline Bile duct and pancreatic diseases (K80-K87) & $298(19.6)$ & $167(38.7)$ & \\
\hline Distribution of diseases at the readmission & & & 0.087 \\
\hline Heart failure (I30-I52) & $34(22.4)$ & $13(26.6)$ & \\
\hline Pneumonia (J09-J18) & $0(0.0)$ & $1(2.0)$ & \\
\hline COPD (J40-J47) & $1(0.6)$ & $1(2.0)$ & \\
\hline Ischemic heart disease (I20-I25) & $23(15.1)$ & $1(2.0)$ & \\
\hline Intestinal diseases (K55-K64) & $17(11.2)$ & $5(10.3)$ & \\
\hline Cerebrovascular disease (I60-I69) & $8(5.3)$ & $1(2.0)$ & \\
\hline Bile duct and pancreatic diseases (K80-K87) & $69(45.4)$ & $27(55.2)$ & \\
\hline \multirow[t]{2}{*}{ Total } & $152(100.0)$ & $49(100.0)$ & \\
\hline & \multicolumn{2}{|c|}{ Mean (SD) } & \multirow{3}{*}{$<0.001$} \\
\hline Duration of hospital stay (days) & $12.8(12.2)$ & $25.4(18.9)$ & \\
\hline Duration of CICW stay (days) & $-\quad-$ & $11.5(10.6)$ & \\
\hline Duration until readmission (days) & $35.4(23.3)$ & $39.9(23.4)$ & 0.246 \\
\hline
\end{tabular}

Table 3 Hazard ratios and 95\% confidence intervals of transferred to community based integrated care ward (CICW) for readmission by frequency and duration of CICW stay

\begin{tabular}{|c|c|c|c|c|c|}
\hline & No & $\mathrm{HR} 1^{\mathrm{a}}$ & $(95 \% \mathrm{CI})$ & $\mathrm{HR} 2^{\mathrm{b}}$ & $(95 \% \mathrm{CI})$ \\
\hline General ward only (reference) & $152 / 1,369$ & 1.00 & & 1.00 & \\
\hline Transferred to CICW & $49 / 367$ & 1.16 & $(0.84-1.61)$ & 0.88 & $(0.61-1.26)$ \\
\hline \multicolumn{6}{|l|}{ Frequency of CICW stay (\%) } \\
\hline $1-35$ & $16 / 124$ & 1.12 & $(0.67-1.88)$ & 0.87 & $(0.51-1.49)$ \\
\hline $35-55$ & $20 / 129$ & 1.32 & $(0.82-2.11)$ & 1.02 & $(0.62-1.68)$ \\
\hline \multirow[b]{2}{*}{$P$ for trend } & $13 / 114$ & 1.03 & $(0.58-1.82)$ & 0.72 & $(0.39-1.31)$ \\
\hline & & \multicolumn{2}{|r|}{0.459} & \multicolumn{2}{|r|}{0.406} \\
\hline \multicolumn{6}{|l|}{ Duration of CICW stay (days) } \\
\hline $1-7$ & $26 / 187$ & 1.19 & $(0.78-1.80)$ & 0.96 & $(0.62-1.49)$ \\
\hline $8-21$ & $16 / 119$ & 1.18 & $(0.70-1.99)$ & 0.84 & $(0.48-1.46)$ \\
\hline$\geq 22$ & $7 / 61$ & 1.05 & $(0.49-2.25)$ & 0.67 & $(0.29-1.56)$ \\
\hline$P$ for trend & & \multicolumn{2}{|r|}{0.487} & \multicolumn{2}{|r|}{0.327} \\
\hline
\end{tabular}

No: number of readmissions / number of no readmissions; HR: hazard ratio; CI: confidence interval. ${ }^{2}$ Adjusted for age and sex. ${ }^{b}$ Adjusted for age, sex, BMI $(<18.5,18.5-24.9, \geq 25.0$, missing), smoking (current / former, never, missing), duration of hospitalization (days), primary disease (heart failure or ischemic heart diseases, intestinal diseases or bile dust and pancreatic diseases), comorbidities (diabetes, cerebrovascular disease, COPD, pneumonia, ischemic heart disease, heart failure, and dementia), and ADL disabilities (independent, low, moderate, high). 
Table 4 Hazard ratios and 95\% confidence intervals for readmission according to home medical care after discharge, hospital support for discharge, and living arrangement by hospitalization status

\begin{tabular}{|c|c|c|c|c|c|c|}
\hline & \multicolumn{6}{|c|}{ Hospitalization status } \\
\hline & \multicolumn{3}{|c|}{ General ward only } & \multicolumn{3}{|c|}{ Transferred to CICW } \\
\hline & No & $\mathrm{HR}^{\mathrm{a}}$ & $(95 \% \mathrm{CI})$ & No & $\mathrm{HR}^{\mathrm{b}}$ & $(95 \% \mathrm{CI})$ \\
\hline \multicolumn{7}{|l|}{ Home-based medical care after discharge } \\
\hline No & $140 / 1,231$ & 1.00 & & $46 / 313$ & 1.00 & \\
\hline Yes & $7 / 81$ & 1.28 & $(0.56-2.94)$ & $2 / 47$ & 0.38 & $(0.08-1.76)$ \\
\hline \multicolumn{7}{|l|}{ Hospital discharge support } \\
\hline No & $124 / 1,027$ & 1.00 & & $31 / 182$ & 1.00 & \\
\hline Discharge support conferences & $19 / 211$ & 0.84 & $(0.50-1.43)$ & $12 / 117$ & 0.62 & $(0.29-1.37)$ \\
\hline Consultation with patients and families & $11 / 110$ & 0.66 & $(0.34-1.29)$ & $7 / 71$ & 0.86 & $(0.36-2.07)$ \\
\hline Coordinating with outside agencies & $18 / 198$ & 0.70 & $(0.40-1.21)$ & $10 / 120$ & 0.40 & $(0.17-0.92)$ \\
\hline \multicolumn{7}{|l|}{ Living arrangement } \\
\hline Living with others & $16 / 223$ & 1.00 & & $14 / 133$ & 1.00 & \\
\hline Living alone & $13 / 93$ & 2.35 & $(1.01-5.47)$ & $5 / 47$ & 0.56 & $(0.15-2.07)$ \\
\hline
\end{tabular}

No: number of readmissions / number of no readmissions; HR: hazard ratio; CI: confidence interval. adjusted for age, sex, BMI ( $<18.5,18.5-24.9, \geq 25.0$, missing), smoking (current / former, never, missing), duration of hospitalization (days), primary disease (heart failure or ischemic heart diseases, intestinal diseases or bile dust and pancreatic diseases), comorbidities (diabetes, cerebrovascular disease, COPD, pneumonia, ischemic heart disease, heart failure, and dementia), and ADL disabilities (independent, low, moderate, high). ${ }^{\mathrm{b}}$ Adjusted for age, sex, BMI (<18.5, 18.5-24.9, $\geq 25.0$, missing), smoking (current / former, never, missing), duration of hospitalization (days), duration of CICW staying (days), primary disease (heart failure or ischemic heart diseases, intestinal diseases or bile dust and pancreatic diseases), comorbidities (diabetes, cerebrovascular disease, COPD, pneumonia, ischemic heart disease, heart failure, and dementia), and ADL disabilities (independent, low, moderate, high).

ditionally, living alone and aging itself may lead to poorer post-discharge treatment compliance, including medication, and the role of social support by family members and other caregivers is important to compensate for this decline ${ }^{22,23)}$. Furthermore, poor medication adherence has been identified as a risk factor for readmission, with low or moderate adherence during hospitalization reported to increase the risk of readmission by approximately 2.5 times $^{24)}$. In this report, patients with lower medication adherence were also found to be more frequently living alone, highlighting the impact of a lack of social support.

A study in Hong Kong reported on the association between social support and readmissions, with patients who used an integrated care and discharge support program for the elderly having decreased readmissions and emergency visits $^{25)}$. The program includes a support system of postdischarge home visits to rehabilitation, food distribution services, home modifications, and the use of caregivers. It has been suggested that the coordination and use of social support may have led to a reduction in readmissions and emergency visits in terms of preserving the physical functioning of the elderly at home and the ability to intervene immediately in the event of an unexpected problem. In the United States, transitional care is an intervention that includes post-acute care and follow-up at community-based care $^{26)}$. A study investing the association between that transitional care and readmissions showed that discharge planning, education about self-management, collaboration among healthcare providers, and follow-up by telephone and home visits have the effect of reducing readmissions, mortality, and acute care resources, and that coordinating with outside healthcare providers to share the information has been reported to facilitate post-discharge support ${ }^{27)}$.

These studies indicate the importance of preventing readmissions with social support. The utilization of social support, even for elderly people living alone, may reduce factors that make continued home-based care difficult, such as poor treatment compliance, medication adherence, and decreased ADL, and consequently reduce readmissions. However, for elderly people who live alone, it is not easy to prepare for social support prior to hospital discharge. In setting up the healthcare environment after discharge, a certain duration of preparation time is needed from the time of hospitalization to coordinate the necessary social resources according to the individual's condition or needs. In the present study, no increased risk of readmission was observed among the elderly living alone who were discharged via a CICW stay, which may indicate that collaboration with outside providers such as care managers and home-visiting nurses may work well as a coordination of the utilization of social resources during hospitalization. The CICW may contribute to the prevention of readmission by taking on the 
role of time-related interventions to create a convalescent environment.

This study has several limitations. First, selection bias due to the subject's hospitalization background needs to be considered. For example, readmissions after discharge might not be to the same medical institute. Therefore, misclassification of readmission cases would occur if the patient was readmitted to a different institution not covered by this study. To reduce these influences as much as possible, the present study was conducted in areas where there was a single medical center in the Medical District. Second, there was no adjustment for potential confounding factors regarding the socio-economic status such as education, household income, and occupation, nutritional status, the severity of the primary disease, and history of medical treatment (including rehabilitation). The criteria for transferring to $\mathrm{CICW}$ were especially unclear. Patients who are more likely to be encouraged to return home may be prioritized for transfer. In the present study, we have attempted to estimate the independent effects of subject status by adding ADL disabilities and comorbidities as adjustment factors in the analysis. Furthermore, the results that there was no reduction in the risk of readmission for hospitalization or duration of CICW stay suggest that interventions to improve the support to return to home rather than just being admitted to a CICW are important in preventing readmission. However, in this study, we could not take into consideration the interventions in practice because of lacking details on hospital discharge support (frequency, number of sessions, and when to be held). In future research, conducting a longitudinal study with a larger population and integrated detailed information about community-based care is necessary.

\section{Conclusion}

The present study observed a decreased risk of readmission among patients discharged from CICW, compared with GW. Although the CICW are unique to Japan and do not provide equivalent interventions as the post-discharge follow-up reported in other Asian and Western countries, it is suggested that collaboration with the outside providers in the CICW may play a role as a coordinator on the part of the medical institution, facilitating a link between the community and patient. Further research is required to clarify the causal factors for this decreased risk.

Conflict of interest: The authors declare that they have no competing interests.

\section{Acknowledgment}

We thank Dr. Ishiguro S, Dr. Iida H, R.N. Motobayashi C, R.N. Tamukai H, and Ms. Tanaka K of the National Hospital Organization Hamada Medical Center for their coordination, supervision, and data collection. We also appreciate the regional medical liaison office staff in the National Hospital Organization Hamada Medical Center for their study support.

\section{References}

1. Song P, Tang W. The community-based integrated care system in Japan: Health care and nursing care challenges posed by super-aged society. Biosci Trends 2019; 13: 279-281. [Medline] [CrossRef]

2. Tsutsui T. Implementation process and challenges for the community-based integrated care system in Japan. Int J Integr Care 2014; 14: e002. [Medline] [CrossRef]

3. Morikawa M. Towards community-based integrated care: trends and issues in Japan's long-term care policy. Int J Integr Care 2014; 14: e005. [Medline] [CrossRef]

4. Ministry of Health, Labor and Welfare in Japan. Medical fee revision in FY 2014. I https://www.mhlw.go.jp/file/06-Seisakujouhou-12400000-Hokenkyoku/0000039380.pdf. (Accessed November 10, 2020)

5. Otsubo T, Imanaka Y. [Readmission rate for health care delivery system assessment]. Nippon Eiseigaku Zasshi 2012; 67: 62-66 (in Japanese). [Medline] [CrossRef]

6. Akao K, Watanabe S, Yagi M, et al. Impact of prehospitalization exercise habits and outpatient cardiac rehabilitation on cardiac readmissions in patients with cardiac disease. JJCR 2018; 24: 219-225 (in Japanese).

7. Wasfy JH, Zigler CM, Choirat C, et al. Readmission rates after passage of the hospital readmissions reduction program: a pre-post analysis. Ann Intern Med 2017; 166: 324-331. [Medline] [CrossRef]

8. Shah T, Churpek MM, Coca Perraillon M, et al. Understanding why patients with COPD get readmitted: a large national study to delineate the Medicare population for the readmissions penalty expansion. Chest 2015; 147: 1219-1226. [Medline] [CrossRef]

9. Dharmarajan K, Hsieh AF, Lin Z, et al. Diagnoses and timing of 30-day readmissions after hospitalization for heart failure, acute myocardial infarction, or pneumonia. JAMA 2013; 309: 355-363. [Medline] [CrossRef]

10. Tsuchihashi M, Tsutsui H, Kodama K, et al. Clinical characteristics and prognosis of hospitalized patients with congestive heart failure-a study in Fukuoka, Japan. Jpn Circ J 2000; 64: 953-959. [Medline] [CrossRef]

11. Fonarow GC, Smith EE, Reeves MJ, et al. Get with the Guidelines Steering Committee and Hospitals Hospital-level variation in mortality and rehospitalization for medicare beneficiaries with acute ischemic stroke. Stroke 2011; 42: 159-166. [Medline] [CrossRef]

12. Hamada city, Shimane prefecture. Hamada City Elderly Welfare Plan 2018. http://www.city.hamada.shimane.jp/www/contents/1515298832835/simple/ koureisyahukusikeikeikaku an.pdf. (Accessed November 29, 2020) 
13. Cabinet Office, Government of Japan The present and future situation of aging. https://www8.cao.go.jp/kourei/whitepaper/w-2020/zenbun/pdf/1s1s_04. pdf. (Accessed November 29, 2020)

14. Parikh MP, Garg R, Chittajallu V, et al. Trends and risk factors for 30-day readmissions in patients with acute cholangitis: analysis from the national readmission database. Surg Endosc 2021; 35: 223-231. [Medline]

15. Ministry of Health, Labor and Welfare in Japan. General Notices Part 2 Admission Materials. https://www.mhlw.go.jp/bunya/iryouhoken/iryouhoken12/dl/ index-010.pdf. (Accessed November 28, 2020)

16. Ministry of Health, Labor and Welfare in Japan. Notice of remarks (Attachment 1, Medicine). https://www.mhlw.go.jp/seisakunitsuite/bunya/kenkou_iryou/iryouhoken/iryouhoken15/d1/2-25-1.pdf. (Accessed April 10, 2021)

17. Donzé J, Lipsitz S, Bates DW, et al. Causes and patterns of readmissions in patients with common comorbidities: retrospective cohort study. BMJ 2013; 347: f7171. [Medline] [CrossRef]

18. Pickens S, Naik AD, Catic A, et al. Dementia and hospital readmission rates: a systematic review. Dement Geriatr Cogn Disord Extra 2017; 7: 346-353. [Medline] [CrossRef]

19. Akita K, Kohno T, Kohsaka S, et al. West Tokyo Heart Failure Registry Investigators Prognostic impact of previous hospitalization in acute heart failure patients. Circ J 2019; 83: 1261-1268. [Medline] [CrossRef]

20. Arbaje AI, Wolff JL, Yu Q, et al. Postdischarge environmental and socioeconomic factors and the likelihood of early hospital readmission among community-dwelling Medicare beneficiaries. Gerontologist 2008; 48: 495-504. [Medline] [CrossRef]

21. Mahoney JE, Eisner J, Havighurst T, et al. Problems of older adults living alone after hospitalization. J Gen Intern Med 2000; 15: 611-619. [Medline] [CrossRef]

22. Silverstein MD, Qin H, Mercer SQ, et al. Risk factors for 30-day hospital readmission in patients $\geq 65$ years of age. Proc Bayl Univ Med Cent 2008; 21 : 363-372. [Medline] [CrossRef]

23. Jankowska-Polańska B, Świątoniowska-Lonc N, Sławuta A, et al. Patient-reported compliance in older age patients with chronic heart failure. PLoS One 2020; 15: e0231076. [Medline] [CrossRef]

24. Rosen OZ, Fridman R, Rosen BT, et al. Medication adherence as a predictor of 30-day hospital readmissions. Patient Prefer Adherence 2017; 11: 801-810. [Medline] [CrossRef]

25. Lin FO, Luk JK, Chan TC, et al. Effectiveness of a discharge planning and community support programme in preventing readmission of high-risk older patients. Hong Kong Med J 2015; 21: 208-216. [Medline]

26. Coleman EA, Parry C, Chalmers S, et al. The care transitions intervention: results of a randomized controlled trial. Arch Intern Med 2006; 166: 1822-1828. [Medline] [CrossRef]

27. Le Berre M, Maimon G, Sourial N, et al. Impact of transitional care services for chronically ill older patients: a systematic evidence review. J Am Geriatr Soc 2017; 65: 1597-1608. [Medline] [CrossRef] 